\title{
CLIMATE CHANGE IMPACT ASSESSMENT ON WATERSHED HYDROLOGY: A COMPARISON OF THREE APPROACHES
}

\author{
${ }^{1}$ Somsubhra Chattopadhyay and ${ }^{2}$ Manoj K. Jha \\ ${ }^{1}$ Department of Computational Science and Engineering, \\ North Carolina A and T State University, NC 27411, Greensboro, USA \\ ${ }^{2}$ Department of Civil, Architectural and Environmental Engineering, \\ North Carolina A and T State University, NC 27411, Greensboro, USA
}

Received 2014-02-08; Revised 2014-02-17; Accepted 2014-03-27

\begin{abstract}
Several methods of impact assessment have been developed over the years which basically incorporate future climate projections of atmospheric-ocean circulation based climate models into the simulation of land surface hydrological processes. This study attempted to evaluate three methods of climate change impact assessment: (a) Frequency perturbation method, (b) direct method and (c) delta change method. A wellcalibrated hydrologic model, Soil and Water Assessment Tool (SWAT), was used in watershed simulation for climate projections of mid-century by ten Global Climate Models (GCMs). The frequency perturbation method found precipitation decrease by $17 \%$ and reduction in temperature by $0.43^{\circ} \mathrm{C}$ on an average annual basis. The changes when applied through the simulation model resulted in $13 \%$ reduction in Evapotranspiration (ET) and $25 \%$ reduction in water yield. Other two methods produced different set of results. It's not conclusive to say which method performed better. The frequency perturbation method produced most extreme changes while direct method had the least magnitude of changes projected for the mid-century. Changes in ET and water yield due to changes in future climate are likely to have severe implications for the water availability. However, more research is needed to evaluate several other impact assessment methods for more reliable analysis.
\end{abstract}

Keywords: Hydrologic Modeling, Climate Change, Impact Assessment, Frequency Perturbation, Delta Change, GCM

\section{INTRODUCTION}

Hydrological cycle has been found to be significantly impacted by the climate change. Intergovernmental Panel for Climate Change (IPCC) reported evidences of strong correlations between the increasing amount of greenhouse gases and aerosols into the atmosphere and the rising global temperature (IPCC, 2007). Warming is projected to be the greatest over northern latitudes and the least in the Southern Ocean and parts of North Atlantic Ocean. The most warming is likely to occur in winter in northern regions and in summer in the south western USA. Accelerated evaporation rates and earlier snowmelt, coupled with the more likelihood of precipitation and temperature extremes, are expected to act as the primary causes for risk of both seasonal floods and recurrent drought episodes (IPCC, 2007).

The impact of climate change on hydrological processes have been investigated in the United States and across the globe during the last decades (Jha et al., 2004; 2006; 2013; Jha and Gassman, 2013; Takle et al., 2005; 2010). Numerous approaches have been applied in these

Corresponding Author: Manoj K. Jha, Department of Civil, Architectural and Environmental Engineering,

North Carolina A and T State University, 1601 E. Market Street, Greensboro, NC 27411, USA Tel: (336) 285-3678 Fax: (336) 334-7126 
studies including regression-based GCM simulations (Stewart et al., 2004), dynamic downscaling of GCMs through nested climate models (Diffenbaugh et al., 2005; Leung and Wigmosta,1999; Leung et al., 2004; Pal and Eltahir, 2002) and coupling of GCMs with hydrologic models (Christensen et al., 2004; Miller et al., 2003). Wilby et al. (2004) pointed out that variations in local climate are mainly governed by the regional physiographic conditions which are not accurately represented by the coarse resolutions of Global Climate Model (GCM) outputs. This adds further uncertainties in the impact assessment. Advances in computer simulation techniques have led to Regional Climate Models (RCMs) with finer resolutions. This has made the forcing of direct output from the RCMs into the hydrologic simulation model possible (Hay et al., 2002; Graham, 2004). However this approach is also questionable if the quality of the RCM output is not good enough.

The delta change method involves altering the observed temperature and precipitation time-series according to the "expected" future change signal from climate models (Hay et al., 2000; Prudhomme et al., 2002). However, keeping the number of wet days unchanged along with discarding potential changes in correlation among different variables might result into neglecting climate variability. Frequency perturbation change method essentially implies transferring the extracted climate change signals to the observed series which accounts for the changes in extreme rainfall events (Taye et al., 2011; Mora et al., 2013). This approach also provides predictions consistent with the occurrence of wet days and wet day rainfall amounts. In this method, rainfall series is perturbed in relation to their frequency of occurrence with a unique factor dependent on return period. Direct method (Takle et al., 2005; 2010) uses direct output of GCM into the hydrologic simulation and thus takes into account more complex changes in the probability functions of the input weather variables into hydrological models. However, bias in the climate model is perpetuated in the assessment, which accounts as a major disadvantage of the direct method.

In this study we examined three methods of climate change impact assessment on watershed hydrology while clarifying some of the issues with the impact assessment studies. Frequency perturbation method, delta change method and direct method were used to quantify the impacts of future climatic information as projected by a suite of 10 GCMs using the hydrologic simulation model, Soil and Water Assessment Tool (SWAT). Variations in the major hydrological variables such as Evapotranspiration (ET), water yield, surface runoff and baseflow were evaluated for the impact assessment.

\section{MODELING APPROACH}

A modeling framework for a large watershed (Raccoon River Watershed, RRW, in Midwest Iowa, USA) having an area of $9,400 \mathrm{~km}^{2}$, developed by (Jha et al., 2007; 2010), was used to test the three methods of climate change impact assessment. Changes in climate projected for the watershed during mid-century (1950s) by 10 GCM simulations driven by the A1B emission scenario (IPCC, 2007) were used in the analyses. The data available were bias-corrected. For detailed information on the climate models used, please refer to (Jha et al., 2013; Jha and Gassman, 2013). The SWAT model was used for hydrologic simulation which was, after a successful calibration, used in combination with climate model projections. SWAT is a long-term, continuous, watershed-scale simulation model that operates on a daily time step and is designed to assess the impact of different management practices on water, sediment and agricultural chemical yields. The model is distributed, computationally efficient and capable of simulating a detailed level of spatial detail (Arnold and Jha, 2012). It simulates the hydrological cycle based on the water balance approach on a daily basis. Major model components are hydrology, weather, soil temperature, crop growth, nutrient, bacteria and land management. SWAT divides a watershed into several subwatersheds which then are further delineated according to unique combination of landuse, soil type and land management practices, called Hydrologic Response Units (HRUs). Water balance is computed for each HRU, which is then aggregated at the subwatershed level. The discharge and associated pollutants from each subwatershed are then routed through the rivers and reservoirs.

\section{IMPACT ASSESSMENT METHODS}

\subsection{Frequency Perturbation Method}

Change in temperature was determined according to the difference between control and scenario projections of the climate models. For the precipitation projection, frequency analysis of quantiles method was used where perturbation factors were obtained by comparing quantiles for given empirical return periods (or values of the same rank) in both the control and scenario series (Mora et al., 2013). This perturbation calculation was performed considering only wet days where a wet day was defined as a day receiving a minimum rainfall amount of $0.1 \mathrm{~mm}$ Equation 1:

Mathematically, $\mathrm{PF}_{\mathrm{i}}=\mathrm{Pr}_{\mathrm{s}} / \mathrm{Pr}_{\mathrm{c}}$ 
where, PF is the perturbation factor, $\mathrm{i}$ is the rank number, $\mathrm{Pr}$ is the rainfall, $\mathrm{s}$ and $\mathrm{c}$ are subscripts denoting scenario and control series respectively. Changes in the wet day frequencies were calculated following quantile perturbation calculation for the wet day rainfall intensities. The day to day variability was addressed through the adjustment of the length of wet and dry spells. We have used a random approach that kept altering the wet and dry spells. Wet spell was defined as any span of time longer than 2 consecutive days receiving more than $0.1 \mathrm{~mm}$ rainfall. The change in mean wet spell length was then calculated from the wet spells in the control and scenario GCM runs on a monthly basis and was adjusted in the observed precipitation timeseries through adding or removing wet days to the beginning or end of the wet spells in the series.

In conclusion, the observed precipitation time-series data was perturbed in two steps, first by removing or adding wet days in the series using the random approach and secondly by applying intensity perturbation to each wet day based on the empirical return period of the rainfall intensity.

\subsection{Direct Method}

Direct method implied executing the hydrologic simulation with the bias-corrected GCM data for both current and future conditions. Contemporary GCM data was used as the baseline scenario while future GCM data was used for the mid-century scenario. SWAT was executed for both scenarios to evaluate the impacts of changed climate.

\subsection{Delta Change Method}

In the delta change method, future climate predictions of GCMs were compared with the contemporary climate predictions to calculate the changes in precipitation and maximum and minimum temperature on a monthly basis for each of the subwatershed. For precipitation monthly percentage change was applied while absolute monthly change was used for temperature series. Historical climatic observations were perturbed using these monthly changes at a subwatershed level.

\section{RESULTS AND DISCUSSION}

All climate models have a range of assumptions for atmospheric circulations under various emission scenarios. Each contains bias in projecting climate variables. This study considered a set of $10 \mathrm{GCMs}$ to hopefully avoid the potential bias that cannot be avoided if considered only one or few climate models. An ensemble approach is used to present results and for discussion where outputs from all 10 Climate Models (GCMs) were averaged for analysis. For hydrologic assessment, hydrologic model SWAT was executed for the baseline historic climate and then for the perturbed climate, produced using three methods.

\subsection{Projected Future Climate}

Figure 1 shows the variations in projections of future climate change (mid-century) as predicted by the ensemble of 10 GCMs. Even with the same set of climate models, different methods produced different values of projections. Following subsections explains the results for each method separately.

\subsubsection{Frequency Perturbation Method}

The watershed was found to have an average of $17 \%$ decrease in monthly precipitation during mid-century. Summer months comprising of May, June, July and August showed an average of $16 \%$ decrease while winter months of December, January and February displayed an $18 \%$ decline. This trend of precipitation over the watershed in mid-century clearly suggests that water scarcity could negatively impact agricultural production during the summer months as crops in the growing season needs more water. This trend in precipitation could also impact the hydrological behavior of the watershed as the water input to the system is substantially reduced in a consistent basis.

Average temperature is projected to decline by $0.43^{\circ} \mathrm{C}$ by mid-century. It has increasing patterns for winter months of November, December and January, but decreasing trend for other months. Winter months evidenced an increase of $0.22^{\circ} \mathrm{C}$ in average temperature while summer months showed a decrease of $1.06^{\circ} \mathrm{C}$.

\subsubsection{Direct Method}

In this method, direct GCM data were used for analysis. It was found that on an average annual basis, precipitation was found to reduce by $1.25 \%$ in midcentury as compared to the baseline climatic conditions. Similarly, annual average temperature was found to reduce by $0.17^{\circ} \mathrm{C}$ in the future. Monthly variations of precipitation revealed mostly decreasing pattern with the exceptions of February, July and November.

\subsubsection{Delta Change Method}

This method implied modifying the observed precipitation and temperature series according to the monthly changes in precipitation and temperature between 
climate models' contemporary and future projections. On an annual average basis, this method found $10 \%$ reduction in precipitation in mid-century compared to the baseline climatic conditions while temperature was found to reduce by $0.43^{\circ} \mathrm{C}$. Variations in precipitation on a monthly basis also followed a decreasing trend in a consistent manner with an average $7 \%$ reduction.

\subsection{Impact on Water Yield as Simulated by SWAT with Projected Climate}

After the future scenarios were developed for precipitation and temperature (as explained in the preceding section), original and perturbed series (from all three methods) were then used to drive the hydrological model to assess the impact of climate change on watershed hydrology. Figure 2 shows the changes in monthly ET, projected to occur in midcentury when determined using three different methods. Results of the two methods (frequency perturbation and delta change) have similarity with consistent changes in their values; however, the third method (direct change) was found to have a totally different response with significantly lower magnitude of the changes. There is a fundamental difference between the first two methods and the third method. The first two are the perturbation methods where information from the climate projections were extracted and perturbed in the historical time-series, whereas the third method uses the direct output of climate models in the hydrologic simulation. The drastic difference in the method-based output warrants the right selection of the method for adoption for the climate change impact assessment.

Similarly, Fig. 3 shows the changes in water yield of the watershed as predicted using three different methods of assessment. Again, all three methods responded differently. Following subsections provide quantitative information on the changes in monthly ET as well as water yield in the watershed.

\subsubsection{Frequency Perturbation Method}

Analysis of the changes in terms of both magnitude and percentage suggest that hydrological components were significantly affected by the climatic conditions of midcentury. Annual average decrease of $17 \%$ precipitation along with decrease of $0.43^{\circ} \mathrm{C}$ average temperature produced significant changes on ET, water yield and thus overall hydrologic balance. Changes in surface runoff and water yield were found to be 48 and $25 \%$ respectively while baseflow was found to be reduced by $8 \%$. ET was found to decline by $13 \%$ in the mid-century with a magnitude of $79 \mathrm{~mm}$ on an annual average basis. Decrease in ET is primarily caused by both reductions in temperature and precipitation. Due to highly nonlinear and complex interactions between the different components of water movement, changes in surface runoff and water yield are not proportional. Water yield was found to decrease by $60 \mathrm{~mm}$ while surface runoff and baseflow was found to decrease by 42 and $11 \mathrm{~mm}$ respectively. Monthly variations of water yield showed a wide range of reduction varying from $8 \%$ in August to $62 \%$ in April.

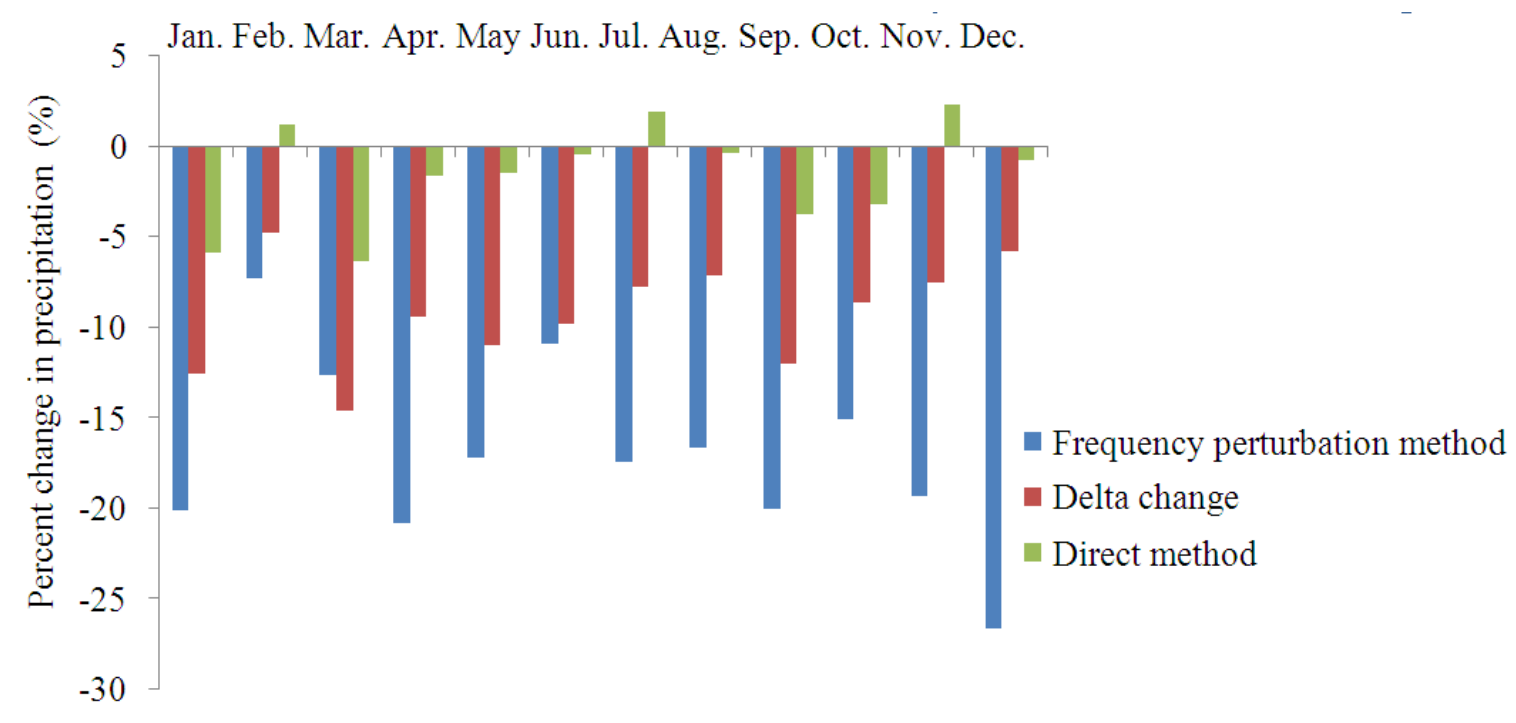

Fig. 1. Comparison of percentage changes in monthly precipitation in the mid-century according to the three different methods 


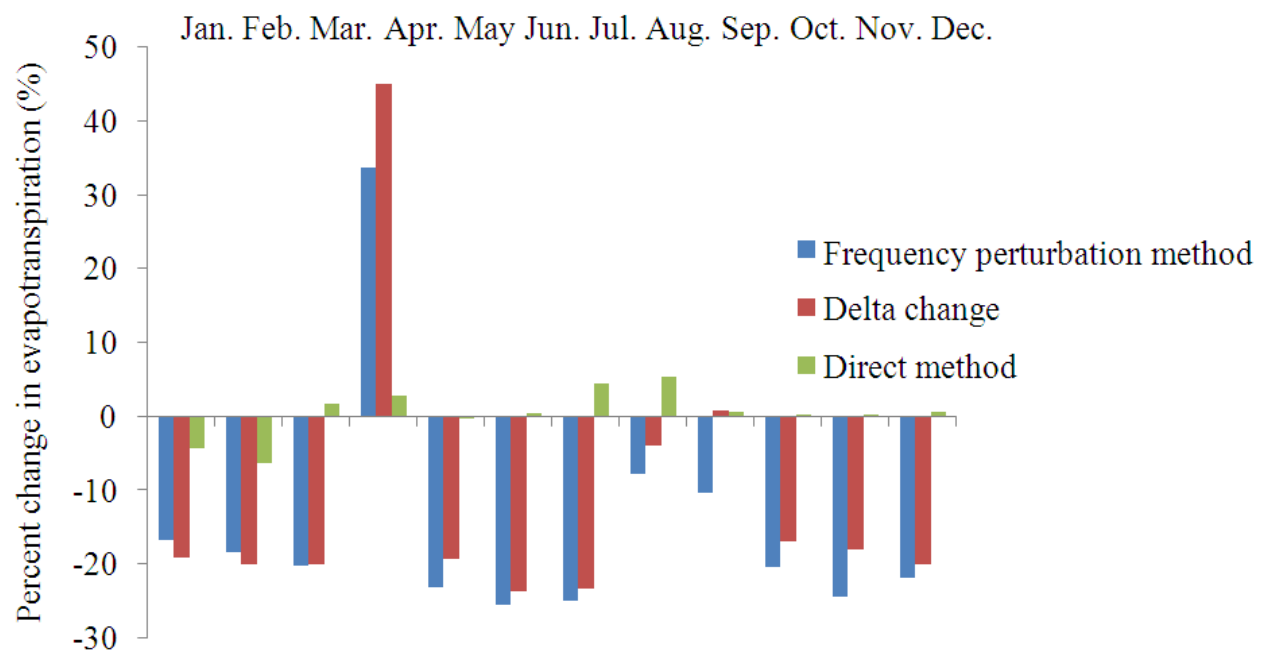

Fig. 2. Monthly comparison of changes in ET in mid-century compared to the baseline

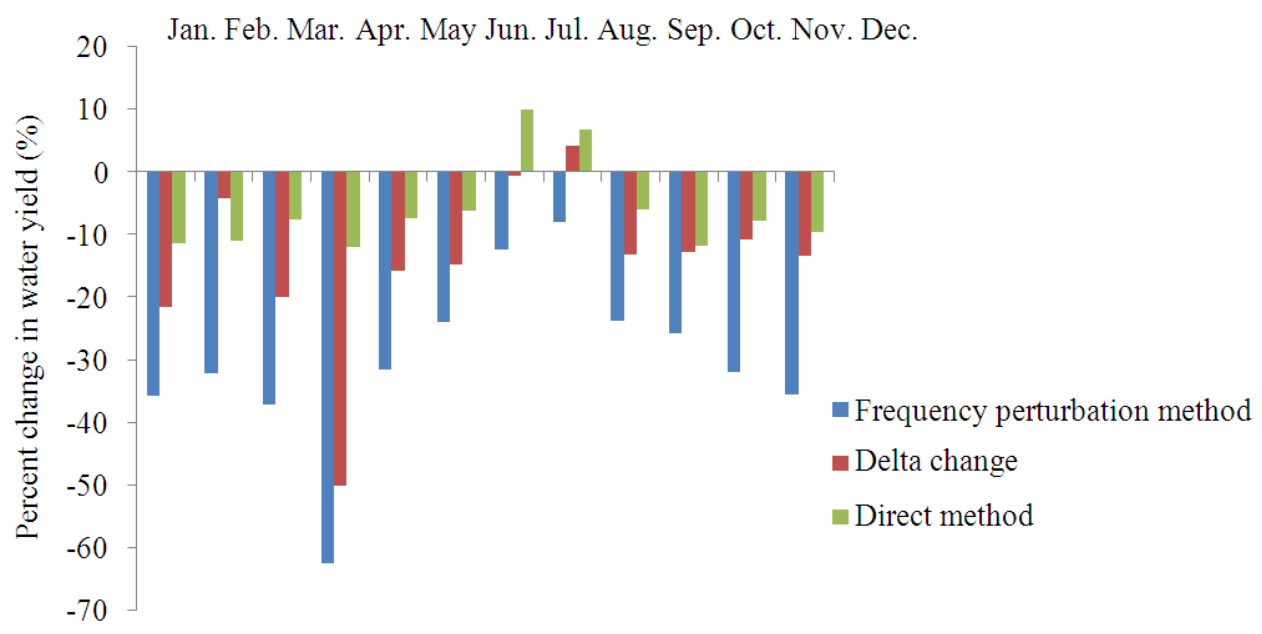

Fig. 3. Comparison of percentage changes in monthly water yield in mid-century as compared to the baseline

April was the highest impact month in terms of reduction in water yield. Winter months are expected to be more affected in terms of water yield reduction with $34 \%$ decline from baseline than summer months where the reduction was $19 \%$. On an average, $30 \%$ reduction was noticed in water yield on a monthly basis which clearly implies RRW might suffer from water scarcity in the mid-century.

ET showed almost a clear decreasing trend for all the months except April when it increased by $34 \%$. Maximum reduction of water yield in April may be due to the increase of ET in April. A 16\% decrease in precipitation in the summer months almost produced proportional results in ET and water yield as they declined by 19 and $20 \%$ respectively. Reason behind decreasing trend of ET is most likely due to the decreasing patterns of precipitation and temperature.

Further analysis identified that the streamflow at the watershed outlet is expected to reduce by $26 \%$ (from 742 to $552 \mathrm{~m}^{3} / \mathrm{s}$ ) on an average annual basis during midcentury. Monthly variations also agreed to the decreasing trend with spring months showing more decrease in flow.

\subsubsection{Direct Method}

This method found an increase in ET by $1.8 \%$ on an average annual basis while water yield was found to decrease by $5 \%$. Possible interpretation of decreasing water yield could be reducing surface 
runoff and baseflow by 2 and $6 \%$ respectively as compared to the baseline.

This method found reductions in small range for winter (December, January and February) and slight increase for summer months. However, frequency perturbation method found steady decrease over all the seasons with the most in winter. Overall, the general trend appears to be that of a reducing nature.

\subsubsection{Delta Change Method}

Water yield followed closely the precipitation pattern of mid-century with only increase found in the month of August. Water yield was found to reduce by $11 \%$ on an annual and $14 \%$ on a monthly basis. Annual ET was found to reduce by $9 \%$.

\section{CONCLUSION}

This study evaluated there methods of assessing climate change impact on watershed hydrology. These methods are frequency perturbation method, direct method and delta change method. All methods agreed that watershed is expected to receive less rainfall and the temperature is also expected to reduce in the mid-century for a watershed condition in the Midwestern USA. Under the frequency perturbation method, precipitation was found to decline by $17 \%$ while average temperature was found to reduce by $0.43^{\circ} \mathrm{C}$. Direct method produced $1.25 \%$ decrease in precipitation while average annual temperature was found to reduce by $0.17^{\circ} \mathrm{C}$. Similarly, the delta change method found $10 \%$ decrease in precipitation and $0.43^{\circ} \mathrm{C}$ reduction in temperature. There are large variations found in the predictions among three methods. Hydrologic impact using SWAT forced by project climates produced a range of outputs under three methods. Frequency perturbation method found ET reduced by $13 \%$ and water yield decreased by $25 \%$. The direct method found an increase of $1.8 \%$ for ET and $5 \%$ reduction in the water yield on an average annual basis. Lastly, the delta change method found $9 \%$ reduction in ET and $11 \%$ reduction in water yield.

Though the magnitude of the changes varied amongst the three methods, general indication was clear and it was inferred that water scarcity could be an alarming issue for this watershed. Frequency perturbation method produced most extreme changes while direct method had the least magnitude of changes projected for the midcentury. Frequency perturbation could be considered to be the most suitable approach for analysis of extreme hydrological events. Delta change method was found to predict the moderate range of changes. By performing the detailed analysis by these methods, it can be concluded that the water resources need to be managed in an efficient way in near future for this region particularly from the agricultural production perspective. Further research is recommended to investigate other techniques including downscaling methods, bias correction and use of broader range of models for more reliable estimates.

\section{REFERENCES}

Arnold, J.G. and M.K. Jha, 2012. SWAT: Model use, calibration and validation. Trans. ASABE, 55: 14911508. DOI: 10.13031/2013.42256

Christensen, S.N., W.A. Wood, N. Voisin, P.D. Lettenmaier and N.R. Palmer, 2004. The effects of climate change on the hydrology and water resources of the Colorado River basin. Climatic Change, 62: 337-363. DOI: 10.1023/B:CLIM.0000013684.13621.1f

Diffenbaugh, N.S., S.J. Pal, J.R. Trapp and F. Giorgi, 2005. Fine-scale processes regulate the response of extreme events to global climate change. Proc. Nat. Acad. Sci. USA., 102: 15774-15778. DOI: 10.1073/pnas.0506042102

Hay, L.E., R.L. Wilby and G.H. Leavesley, 2000. A comparison of delta change and downscaled $\mathrm{gcm}$ scenarios for three mounfainous basins in the United States. J. Am. Water Resour. Assoc., 36: 387-397. DOI: 10.1111/j.1752-1688.2000.tb04276.x

Jha, M.K. and P.W. Gassman, 2013. Changes in hydrology and streamflow as predicted by a modelling experiment forced with climate models. Hydrol. Process., 28: 2772-27181. DOI: 10.1002/hyp.9836

Jha, M.K., C.F. Wolter, P.W. Gassman and K.E. Schilling, 2010. Assessment of total maximum daily load implementation strategies for nitrate impairment of the raccoon river, Iowa. J. Environ. Q., 39: 1317-1327. DOI: 10.2134/jeq2009.0392

Jha, M.K., J.G. Arnold and P.W. Gassman, 2007. Water quality modeling for the raccoon river watershed using SWAT. Trans. ASABE, 50: 479-493. DOI: 10.13031/2013.22660

Jha, M.K., J.G. Arnold, P.W. Gassman, F. Giorgi and R. $\mathrm{Gu}, 2006$. Climate change sensitivity assessment on Upper Mississippi River Basin streamflows using SWAT. J. Am. Water Resour. Assoc., 42: 997-1016. DOI: $10.1111 /$ j.1752-1688.2006.tb04510.x 
Jha, M.K., P.W. Gassman and Y. Panagopoulos, 2013. Regional changes in nitrate loadings in the Upper Mississippi River Basin under predicted mid-century climate. Regional Environ. Change. DOI: 10.1007/s.10113-013-05539-y

Jha, M.K., Z. Pan, E.S. Takle and R. Gu, 2004. Impacts of climate change on streamflow in the Upper Mississippi River Basin: A regional climate model perspective. J. Geophys. Res. DOI: 10.1029/2003JD003686

Leung, L.R. and M.S. Wigmosta, 1999. Potential climate change impacts on mountain watersheds in the Pacific Northwest. J. Am. Water Resour. Assoc., 35: 1463-1471. DOI: $\quad 10.1111 / \mathrm{j} .1752-$ 1688.1999.tb04230.x

Leung, R.L., Y. Qian, X. Bian, M.W. Washington and J. Han et al., 2004. Mid-century ensemble regional climate change scenarios for the Western United States. Climate Change, 62: 75-113. DOI: 10.1023/B:CLIM.0000013692.50640.55

Miller, N.L., E.K. Bashford and E. Strem, 2003. Potential impacts of climate change on California hydrology. J. Am. Water Resour. Assoc., 39: 771784. DOI: $10.1111 / j .1752-1688.2003 . t b 04404 . x$

Mora, D.E., L. Campozano, F. Cisneros, G. Wyseure and P. Willems, 2013. Climate changes of hydrometeorological and hydrological extremes in the Paute basin, Ecuadorean Andes. Hydrol. Earth Syst. Sci. Discuss., 10: 6445-6471. DOI: 10.5194/hessd-10-6445-2013

Pal, J.S. and E.A.B. Eltahir, 2002. Teleconnections of soil moisture and rainfall during the 1993 Midwest summer flood. Geophys. Res. Lett., 29: 12-1-12-4. DOI: $10.1029 / 2002$ GL014815
Prudhomme, C., N. Reynard and S. Crooks, 2002. Downscaling of global climate models for flood frequency analysis: Where are we now? Hydrol. Process., 16: 1137-1150. DOI: 10.1002/hyp.1054

Stewart, I.T., R.D. Cayan and D.M. Dettinger, 2004. Changes in snowmelt runoff timing in western north america under a 'business as usual' climate change scenario. Climate Change, 62: 217-232. DOI: 10.1023/B:CLIM.0000013702.22656.e8

Takle, E.S., M.K. Jha and C.J. Anderson, 2005. Hydrological cycle in the Upper Mississippi River Basin: 20th century simulations by multiple GCMs. Geophys. Res. Lett. DOI: 10.1029/2005GL023630

Takle, E.S., M.K. Jha, E. Lu, R.W. Arritt and W.J. Gutowski et al., 2010. Streamflow in the Upper Mississippi River Basin as simulated by SWAT driven by 20th Century contemporary results of global climate models and NARCCAP regional climate models. Meteorol. Zeitschift, 19: 341-346. DOI: 10.1127/0941-2948/2010/0464

Taye, M.T., V. Ntegeka, N. Ogiramoi and P. Willems, 2011. Assessment of climate change impact on hydrological extremes in two source regions of the Nile River Basin. Hydrol. Earth Syst. Sci., 15: 209222. DOI: 10.5194/hess-15-209-2011

Wilby, R.L., S.P. Charles, E. Zorita, B. Timbal and P. Whetton et al., 2004. Guidelines for use of climate scenarios developed from statistical downscaling methods: Supporting material of the intergovernmental panel on climate change.

Graham, H., 2004. Social determinants and their unequal distribution: Clarifying policy understandings. Milbank Q., 82: 101-124. DOI: 10.1111/j.0887378X.2004.00303.x

IPCC, 2007. Climate Change 2007: The Physical Science Basis. Intergovernmental Panel on Climate Change. 